\title{
Controle genético da regeneração in vitro em progênies de Eucalyptus grandis
}

\author{
Genetic control of in vitro regeneration of Eucalyptus grandis
}

\author{
Carlos David Vera Bravo ${ }^{I}$ Antônio Natal Gonçalves ${ }^{\text {II }}$ Carlos Tadeu dos Santos Dias ${ }^{\text {III }}$ \\ Roland Vencovsky ${ }^{\mathrm{IV}}$
}

RESUMO

Com o objetivo de avaliar o controle genético da regeneração direta in vitro a partir de plântulas de Eucalyptus grandis, foram utilizadas sementes de 10 progênies de polinização aberta da população base, origem Atherton, localizada em Anhembi, Estado de São Paulo. Vinte dias de cultivo após a germinação, 196 segmentos distais dos hipocótilos por progênie foram inoculados in vitro num Delineamento em Blocos Completos Aleatorizado Generalizado, com duas unidades experimentais por bloco e sete repetições por bloco, usando a interação blocos por progênie como estimadora do erro experimental. Após 14 semanas de cultivo, foram feitas avaliações da regeneração. Houve diferenças significativas de regeneração entre as progênies $(P<0,0001)$ com extremos de regeneração de $11 \%$ a $60 \%$. A herdabilidade no sentido restrito entre as médias das unidades experimentais do caráter foi alta $\left(h^{2}=0,94\right)$, indicando que houve um forte controle genético na regeneração in vitro dentro da população. Houve também alta variabilidade dentro da amostra estudada, assim como um forte efeito do progenitor materno sobre a regeneração.

Palavras-chave: regeneração in vitro, controle genético, Eucalyptus grandis, herdabilidade.

\section{AbSTRACT}

The genetic control of in vitro direct regeneration was tested on seedlings of ten open-pollinated progenies from the base population of Atherton origin of Eucalyptus grandis at University of São Paulo (Brazil). Seeds were germinated in vitro, after twenty days, distal hypocotyls segments from 196 seedlings per progeny were inoculated in culture media at Generalized Complete Randomized Block Design, with two experimental units per block and seven repetitions, using the interaction blocks by progenies as an estimate of the experimental error. At week 14 from the inoculation bud induction was evaluated. Regeneration among progenies were significantly different $(P<0.0001)$. Regeneration varied from 11 to $60 \%$. The narrow-sense heritability between means of experimental units for in vitro regeneration was height. $\left(h^{2}=0.94\right)$, indicating a strong genetic control of the trait within the $e^{m}$ population and also a high maternal effect. High variability within the study sample was found.

Key words: in vitro regeneration, genetic control, Eucalyptus grandis, heritability.

\section{INTRODUÇÃO}

O sucesso na exploração industrial de eucaliptos no Brasil foi baseado, desde sua introdução até o desenvolvimento da propagação clonal (CAMPINHOS \& IKEMORI, 1983) durante as últimas décadas, nos programas de melhoramento. Nesse contexto, a estimação de parâmetros genéticos, sua comparação entre orígenes, progênies e métodos de propagação e uso na predição de ganhos genéticos são úteis no melhoramento (KAGEYAMA \& KIKUTI, 1981, OSÓRIO et al., 2001).

A propagação in vitro tem contribuído na regeneração de espécies, híbridos e clones de eucaliptos, por meio da organogênese (BANDYOPADHYAY et al., 1999; BARRUETO-CID et al., 1999; SARTORETTO et al., 2002), embriogênese somática (BANDYOPADHYAY

IInstituto Nacional de Tecnologia Agropecuária (INTA), Bella Vista. CC n.5, CP 3432, Bella Vista, Corrientes, Argentina.

IIDepartamento de Ciências Florestais, Escola Superior de Agricultura Luiz de Queiroz (ESALQ), Universidade de São Paulo (USP), Piracicaba, SP, Brasil.

IIIDepartamento de Ciências Exatas, ESALQ, USP, Piracicaba, SP, Brasil. E-mail: ctsdias@esalq.usp.br. Autor para correspondência.

${ }^{\text {IV }}$ Departamento de Genética, ESALQ, USP, Piracicaba, SP, Brasil. 
et al., 2000; HERVÉ et al., 2001; PINTO et al., 2002) e brotação de gemas laterais SOBROSA \& CORDER, 2003). As diferenças entre progênies sugerem a existência de fatores genéticos que controlam o caráter, estando associados aos processos de desenvolvimento in vitro (CHRISTIANSON \& WARNICK, 1988). Além disso, a nutrição mineral também participa na regulação morfogênica (RAMAGE \& WILLIAMS, 2002), assim como o balanço dos reguladores de crescimento determina o potencial de regeneração (ZAFFARI et al., 2000).

A regeneração de progênies a partir de tecidos juvenis é uma alternativa para regenerar progênies, comparar caracteres in vitro e in vivo, testar clones a partir destas progênies e dispor de sistemas de regeneração visando à transformação genética que requer um sistema eficiente de regeneração.

Variações genéticas foram encontradas entre famílias e dentro de famílias em Eucalyptus grandis quanto à capacidade de formação de gemas (SOBROSA \& CORDER, 2003). RUAUD et al. (1999), estudando a habilidade de enraizamento in vitro de Eucalyptus globulus, detectaram variações genéticas aditivas significativas, indicando que há um potencial para o melhoramento deste caráter para esta espécie.

A maioria dos trabalhos que determinam parâmetros genéticos em Eucalyptus grandis visa à produtividade e a características da madeira (KAGEYAMA \& VENCOVSKY, 1983; OSÓRIO et al., 2001; MORAES, 1987; SANTOS etal., 2004). O presente trabalho teve como objetivo avaliar a variabilidade genética e o caráter herdável da regeneração in vitro de Eucalyptus grandis.

\section{MATERIAL E MÉTODOS}

As sementes utilizadas foram coletadas de árvores matrizes com 23 anos de idade, de 10 progênies de Eucalyptus grandis de polinização aberta, pertencentes à população base de origem Atherton QLD/Austrália e encontra-se no município de Anhembi (SP) Brasil.

Foram elaborados meios de cultura com o meio basal de JADS (CORREIA et al., 1995) sem hormônios de crescimento. Cada frasco teve $40 \mathrm{~mL}$ de meio e foram inoculadas 20 sementes por frasco e 16 frascos por progênie. As sementes foram desinfetadas por uma hora com água sanitária comercial 100\% (2$2,5 \% \mathrm{p} / \mathrm{v}$ de $\mathrm{NaOCl}$ ) com adição de 10 gotas de Tween 20 a cada $30 \mathrm{~mL}$ do produto, seguido por seis lavagens com água destilada e esterilizada. Das plântulas de 20 dias de idade, foram extraídos os hipocótilos distais (uma porção do hipocótilo, da parte mais distal da raiz, sem nó cotiledonar) de 0,7 a $1 \mathrm{~cm}$ de comprimento e inoculados no meio de cultura JADS (CORREIA et al.,
1995) com $0,5 \mathrm{mg} \mathrm{L}^{-1}$ de ANAe $0,5 \mathrm{mg} \mathrm{L}^{-1}$ de BAP, sendo que o explante e o meio foram determinados previamente (BRAVO, 2005). O pH dos meios foi ajustado a 5,8 antes da esterilização em autoclave a $121^{\circ} \mathrm{C}$ durante $20 \mathrm{~min}$. As culturas foram mantidas em sala de crescimento durante os primeiros quatro dias no escuro e posteriormente foram mantidas a $50 \mu \mathrm{mol}$ $\mathrm{m}^{-2} \mathrm{~s}^{-1}$ de radiação fotossinteticamente ativa (PAR), sob fotoperíodo de $12 \mathrm{~h}$ e temperatura de $25 \pm 2^{\circ} \mathrm{C}$.

O delineamento experimental utilizado foi em Blocos Completos Aleatorizado Generalizado (STEEL \& TORRIE, 1980), em que as progênies foram aleatorizadas em sete blocos com duas repetições (dois frascos) por bloco, usando a interação blocos por progênie como estimadora do erro experimental. Em cada frasco (unidade experimental), foram inoculadas 14 hipocótilos distais, totalizando 196 explantes (genótipos) por progênie. A resposta de regeneração (\%) foi examinada por meio da análise da variância, sendo que também foram calculados intervalos de confiança. Os valores de probabilidade (P) obtidos foram calculados pelo procedimento anova do Sistema Computacional Estatístico SAS (1999).

O modelo utilizado para análise dos dados foi: $Y_{i j k}=m+t_{i}+b_{j}+e_{i j}+d_{i j k}$ em que: $Y_{i j k}-$ valor da observação $\mathrm{k}$, no tratamento i do bloco j; $m$ - média da população, sem considerar o efeito de tratamento; $t_{i}$ efeito devido à progênie $i, \operatorname{com} i=1,2, \ldots, 10 ; b_{j}$ - efeito devido ao bloco $\mathrm{j}, \operatorname{com} \mathrm{j}=1,2, \ldots, 7 ; e_{i j}$ - efeito devido aos fatores não-controlados, na parcela que recebeu $o$ tratamento i, do bloco $\mathrm{j} ; d_{i j \mathrm{k}}$ - efeito da observação $\mathrm{k}$, dentro do tratamento i, no bloco $\mathrm{j}$, com $\mathrm{k}=1,2$.

A tabela 1 apresenta o esquema da análise da variância segundo o modelo anterior. Por essa tabela, é possível perceber que o efeito de progênie é testado com o erro experimental.

As unidades de análise para calcular a herdabilidade foram as médias das parcelas. A estimativa do coeficiente de herdabilidade no sentido restrito foi calculada considerando as médias das famílias, para o caráter em estudo.

As estimativas de variâncias genéticas e ambientais e de parâmetros afins para a característica regeneração in vitro foram obtidas pela decomposição do quadrado médio das progênies em função da sua esperança matemática. Foram obtidas as seguintes estimativas para obter o coeficiente de herdabilidade:

$\hat{\sigma}_{e}^{2}=\frac{Q M_{e . \exp }-Q M_{d}}{2} ; \hat{\sigma}_{p}^{2}=\frac{Q M_{p}-Q M_{e . \exp }}{14} ;$

$\hat{\sigma}_{d}^{2}$ : Variância dentro do bloco entre parcelas. 
Tabela 1 - Esquema de análise da variância correspondente a uma seleção entre as médias das parcelas.

\begin{tabular}{llll}
\hline Fonte de variação & $\mathrm{GL}$ & $\mathrm{QM}$ & $\mathrm{E}(\mathrm{QM})$ \\
\hline Blocos & $\mathrm{b}-1$ & $\mathrm{QM}_{\mathrm{b}}$ & ---------- \\
Progênies & $\mathrm{p}-1$ & $\mathrm{QM}_{\mathrm{p}}$ & $\sigma_{d}^{2}+n \sigma_{e}^{2}+n b \sigma_{p}^{2}$ \\
Erro & $(\mathrm{b}-1)(\mathrm{p}-1)$ & $\mathrm{QM}_{\mathrm{e} \text {.xp }}$ & $\sigma_{d}^{2}+n \sigma_{e}^{2}$ \\
Erro dentro & $(\mathrm{n}-1) \mathrm{bp}$ & $\mathrm{QM}_{\mathrm{d}}$ & $\sigma_{d}^{2}$ \\
Total & $\mathrm{bpn}-1$ & & \\
\hline
\end{tabular}

O coeficiente de herdabilidade correspondente a uma seleção entre as médias de meiosirmãos foi obtido a partir da seguinte expressão (VENCOVSKY \&BARRIGA, 1992):

$$
\hat{h}_{m}^{2}=\frac{\hat{\sigma}_{p}^{2}}{\hat{\sigma}_{p}^{2}+\frac{\hat{\sigma}_{e}^{2}}{r}+\frac{\hat{\sigma}_{d}^{2}}{n r}},
$$

em que: $\hat{\sigma}_{p}^{2}$ : componente da variância devido às progênies; $\hat{\sigma}_{e}^{2}$ : componente da variância do erro experimental; $\hat{\sigma}_{d}^{2}$ : componente da variância dentro do bloco, entre parcelas; r: número de repetições; n: número de parcelas por tratamento por bloco. Em todas as análises estatísticas utilizadas no presente trabalho foi utilizado o nível de significância de $5 \%(\alpha=0,05)$.

\section{RESULTADOS E DISCUSSÃO} das progênies

Avaliação da capacidade de regeneração

As progênies apresentam diferenças significativas quanto à capacidade de regeneração in vitro. $\mathrm{O}$ teste $\mathrm{F}$ relativo a progênies feito após transformação dos dados, para a transformação arco seno $(\sqrt{\text { porcentagem }})$ forneceu o valor $\mathrm{F}=6,55^{* *}(\mathrm{gl}$ $9 ; 54)$.

$\mathrm{Na}$ tabela 2 tem-se que os coeficientes de variação para o erro experimental e para o erro dentro foram C. $V_{\text {e.exp }}(\%): 36,8$ e C.V $V_{d}(\%): 29,6$, respectivamente, enquanto a Média geral da Regeneração ficou em 36,77 .
Para as componentes da variância, foram obtidos os seguintes valores, $\hat{\sigma}_{p}^{2}=232,96$, $\hat{\sigma}_{e}^{2}=32,29, \hat{\sigma}_{d}^{2}=118,42$ e assim o coeficiente de herdabilidade foi de 0,946 .

O erro experimental no ensaio da regeneração in vitro dentro de cada progênie foi baixo, como pode ser visto nos intervalos de confiança para as médias de progênies da figura 1. A variabilidade entre as progênies foi alta, variando desde $11 \%$ até 60 $\%$ de regeneração, indicando diferenças acentuadas entre progênies (Tabela 1).

O coeficiente de variação experimental $(36,8 \%)$ de progênies para o caráter estudado foi alto, porém, o número de repetições foi suficiente (Tabela 2) para compensar essa baixa precisão, a qual provavelmente deve-se ao fato que cada explante representa um genótipo diferente dentro das progênies.

$\mathrm{O}$ quadrado médio que estima a variação entre parcelas dentro de cada bloco também foi baixo (Tabela 2), o que indica a ocorrência da homogeneidade da regeneração entre as parcelas dentro do mesmo bloco.

Como foram fixados o meio de cultura e o explante e ante uma acentuada diferença de organogênese entre progênies, isso indicaria que são poucos (HENRY et al., 1994) e dispersos os genes que estariam controlando este caráter dentro da população. Em conseqüência, há influência do genótipo na capacidade organogénica nestas progênies. Estas diferenças entre genótipos foram observadas tanto em espécies arbóreas como herbáceas (PARK et al., 1993;

Tabela 2 - Esquema de análise da variância correspondente a uma seleção entre as médias das parcelas.

\begin{tabular}{|c|c|c|c|c|}
\hline Fonte de variação & GL & SQ & QM & $\mathrm{E}(\mathrm{QM})$ \\
\hline Blocos & 6 & 1647,1096 & $274,5182^{\text {ns }}$ & |----------- \\
\hline Progênies & 9 & 31000,34 & $3444,4828^{* * *}$ & $\sigma_{d}^{2}+n \sigma_{e}^{2}+n b \sigma_{p}^{2}$ \\
\hline Erro & 54 & 9882,68 & 183,0127 & $\sigma_{d}^{2}+n \sigma_{e}^{2}$ \\
\hline Erro dentro & 70 & 8289,47 & 118,4210 & $\sigma_{d}^{2}$ \\
\hline Total & 139 & 50819,61 & & ------------ \\
\hline
\end{tabular}

*** Significativo em nível de 0,05 pelo teste $\mathrm{F}$. 


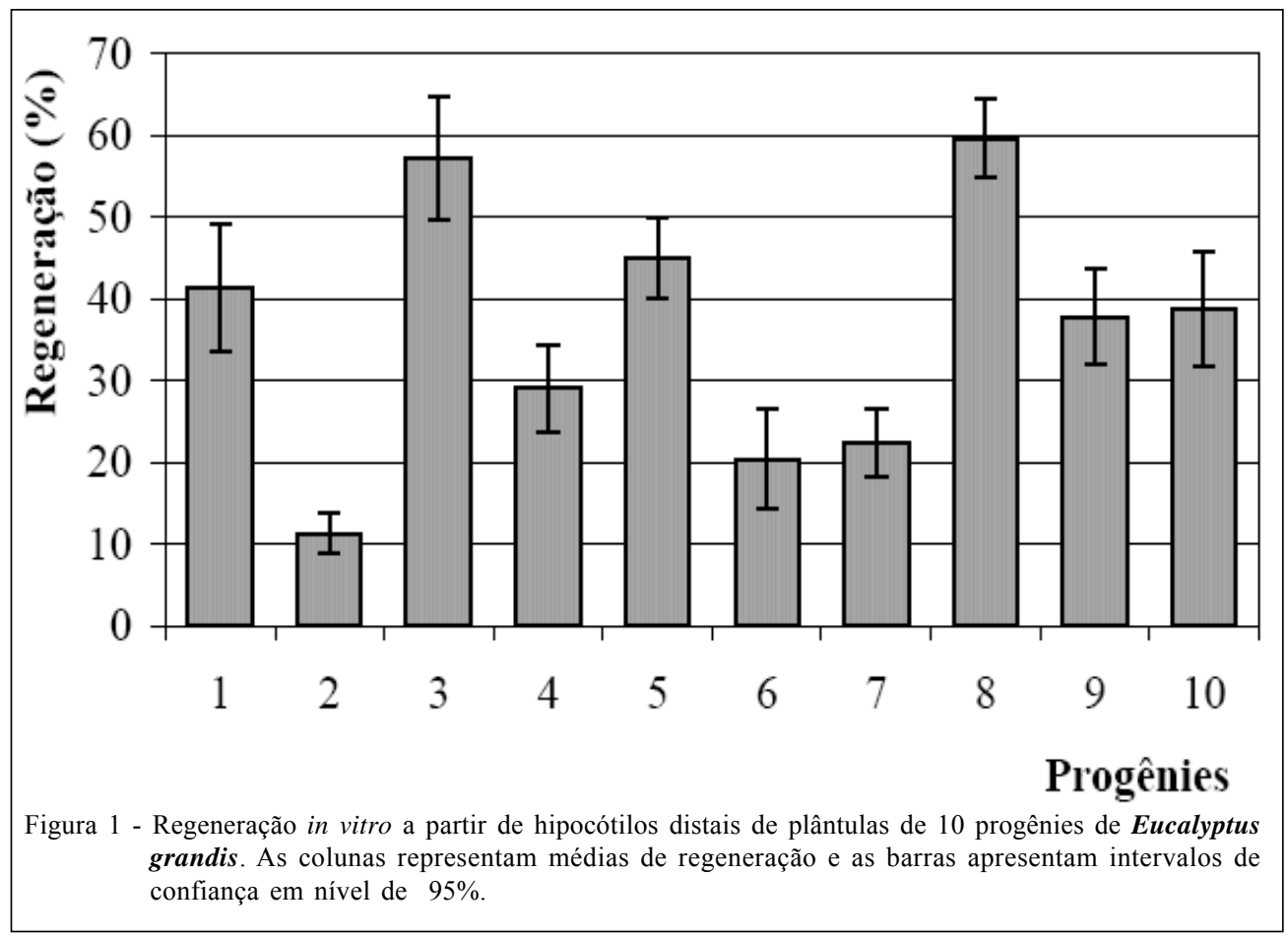

LAINÉ \& DAVID, 1994; NESTARES et al., 2002). Elas poderiam servir para estudar outros caracteres in vitro e correlacionar estes com os expressados in vivo. A partir da observação da figura, 1 pode-se afirmar que a variação genética entre progênies foi maior do que dentro de progênies. Porém, a seleção para regeneração in vitro deve ser mais eficiente entre médias de famílias do que dentro de famílias, fato também observado por SOBROSA \& CORDER, (2003) e RUAUD et al. (1999) no estudo da brotação e do enraizamiento in vitro em E. grandis e E. globulus respectivamente.

Melhorar genótipos com caracteres in vitro, como o enraizamento em Eucalyptus globulus, reportado por RUAUD et al. (1999), abre a possibilidade de transferir caracteres de interesse a genótipos mais recalcitrantes, embora sejam limitados estudos em eucaliptos ainda.

Os resultados indicam que é possível trabalhar no melhoramento dos genótipos utilizados no presente estudo. A variância genética aditiva foi o maior componente da variância genética e a herdabilidade estimada foi alta, indicando que a estratégia de melhoramento por seleção recorrente (KIELLY \& BOWLEY, 1997) para o caráter regeneração direta in vitro seria perfeitamente realizável.

A polinização nesta espécie é cruzada (CHAIX et al., 2003), porém, a regeneração in vitro nesta amostra, tem uma forte influência do progenitor materno, pois a variabilidade dentro de cada progênie foi pequena, como mostram os intervalos de confiança. Dado que são poucos os genes que controlam este caráter, há possibilidade de uma relativamente rápida incorporação destes caracteres em outros genótipos.

O quadrado médio baixo do erro experimental indica que as condições in vitro foram ótimas para diferenciar a alta variabilidade entre famílias quanto à organogênese. No entanto, neste experimento não foi demonstrado o efeito da interação genótipo e ambiente, fato que acontece normalmente em sistemas de cultura in vitro (NESTARES et al., 2002; GOPAL, 2001), o que afetaria o coeficiente de herdabilidade. O uso de reguladores de crescimento, ANA e BAP $\left(0,5 \mathrm{mgL}^{-1}\right.$ cada), e o explante na regeneração destas progênies foram eficientes.

\section{CONCLUSÕES}

A população base estudada apresenta variabilidade genética entre as progênies de polinização aberta aqui testada quanto ao caráter regeneração in vitro, mostrando um potencial para ser explorado na seleção, afim de transferir para genótipos superiores que possam ser utilizados em programas de melhoramento.

A herdabilidade encontrada entre progênies dentro da amostra foi alta, indicando que $94 \%$ da variação da regeneração in vitro está relacionada a fatores genéticos exploráveis no melhoramento. 


\section{REFERÊNCIAS}

BANDYOPADHYAY, S. et al. Efficient plant regeneration from seedling explants of two commercially important temperate eucalypt species - Eucalyptus nitens and Eucalyptus globulus. Plant Science, Washington, v.140, p.189-198, 1999.

BANDYOPADHYAY, S.; HAMILL J.D. Ultra structural studies of somatic embryos of Eucalyptus nitens and comparisons with zygotic embryos found in mature seeds. Annals of Botany, Oxford, v.86, n.2, p.237-244, 2000.

BARRUETO-CID, L.P. Plant regeneration from seedling explants of Eucalyptus grandis x Eucalyptus urophylla. Plant Cell, Tissue and Organ Culture, Netherlands, v.56, n.1, p.17-23, 1999.

BRAVO, V.C.D. Controle genético e histogênese na regeneração de progênies de Eucalyptus grandis in vitro. 2005. 80f. Dissertação (Mestrado em Recursos Florestais) Curso de Pós-graduação em Ciências Florestais, Universidade de São Paulo.

CAMPINHOS, E.J.; IKEMORI, Y.K. Nova técnica para produção de mudas de essências florestais. IPEF, Piracicaba, New York, v.23, p.47-52, 1983.

CHAIX, G. et al. Gene flow estimation with microsatellites. in a Malagasy seed orchad of Eucalyptus grandis. Theoretical and Applied Genetics, New York, v.107, p.705-712, 2003.

CORREIA, D. et al. Efeito do meio de cultura líquido e sólido no crescimento e desenvolvimento de gemas de Eucalyptus grandis $\mathrm{x}$ Eucalyptus urophylla na multiplicação in vitro. IPEF, Piracicaba, v.48-49, p.107-116, 1995.

CHRISTIANSON, M.L.; WARNICK, D.A. Organogenesis in vitro as a developmental process. HortScience, St. Joseph, v. 23, p. $515-519,1988$.

GOPAL. J. In vitro and in vivo genetic parameters and character associations in potato. Euphytica, Netherlands, v.118, p.145151,2001

HENRY, Y. et al. Genetic analysis of in vitro plant tissue culture responses and regeneration capacities. Euphytica, Netherlands, v.79, p.45-58, 1994

HERVÉ, P. et al. A procedure for shoot organogenesis in vitro from leaves and nodes of an elite Eucalyptus dunnii clone: comparative histology. Plant Science, Washington, v.161, p.645-653, 2001

KAGEYAMA, P.Y.; KIKUTI, P. Comparison between clones and open-pollinated progenies originating from a population of Eucalyptus grandis (Hill) Maiden in Brazil. In BRREDING TROPICAL TREES: POPULATION ESTRUTURE AND GENETIC IMPROVEMENT ATRATEGIES IN CLONAL AND SEEDLING FORESTRY, 1981., Pattaya, Thailand. Proceedings... Pattaya: Oxford Forestry Institute, Winrock International, 1981. p.227-235.

KAGEYAMA, P.Y.; VENCOVSKY, R. Variação genética em progênies de uma população de Eucalyptus grandis (Hill) Maiden. IPEF, Piracicaba, n.24, p.9-26, 1983.

KIELLY, G.A.; BOWLEY, S.R. Quantitative genetic analysis of in vitro callus proliferation in alfalfa. Canadian Journal of Plant Science, Ottawa, v.77, p.225-229, April. 1997.
LAINÉ, E.; DAVID, A. Regeneration of plants from leaf explants of micropropagated clonal Eucalyptus grandis. Plant Cell Reports, Würzburg, v.13, p.473-476, 1994.

MORAES, M.L.T. de. Variação genética da densidade básica da madeira em progênies de Eucalyptus grandis Hill ex Maiden e suas relações com as características de crescimento. 1987. 115f. Dissertação (Mestrado em ciências Florestais) - Escola Superior de Agricultura "Luiz de Queiroz", Universidade de São Paulo, Piracicaba.

NESTARES, G. et al. Heritability of in vitro plant regeneration capacity in sunflower. Plant Breeding, Berlin, v.121, p.366368,2002

OSÓRIO, L.F. et al. Age trends of heritabilities and genotypeby-enviroment interactions for growth and woods sensity from clonal trials of Eucalyptus grandis Hill ex Maiden. Silvae Genética, Frankfurt, v.50, p.30-37, 2001.

PARK, Y.S. et al. Initiation of somatic embryogenesis in white spruce (Picea glauca): genetic control, culture treatment effects, and implications for tree breeding. Theoretical and Applied Genetics, New York, v.86, p.427-436, 1993.

PINTO, G. et al. Somatic embryogenesis and plant regeneration in Eucalyptus globulus Labill. Plant Cell Reports, New York, v.21, n.3, p.208-213, 2002

RUAUD, J.N. et al. Genetic variation of in vitro rooting ability with time in Eucalyptus globulus. Silvae Genética, Frankfurt, v.48, p.4-7, 1999

RAMAGE, C.M.; WILLIAMS, R.R. Mineral nutrition and plant morphogenesis. In Vitro Cellular Development BiologyPlant, Gaithersburg, v.38, p.116-124, 2002.

SANTOS P.E.T. et al. Estimates of genetic parameters of woods traits for timber production in Eucalyptus grandis. enetics and Molecular Biology, Ribeirão Preto, v. 27, n.4, p.567-573, 2004

SAS Institute Inc. The SAS System. Release 8.2, SAS Institute, Cary, 1999.

SARTORETTO, L.M. et al. Biolistic transformation of Eucalyptus grandis X Eucalyptus urophylla callus. Functional Plant Biology, Victoria, v.29, n.8, p.917-924, 2002.

SOBROSA, R. de C.; CORDER, M.P.M. Efeito do genótipo sobre o potencial para produção de gemas adventícias em Eucalypus grandis Hill ex Maiden in vitro. Floresta e Ambiente, Rio de Janeiro, v.10, p.58-68, 2003.

STEEL, R.G.D.; TORRIE, J.H. Principles and procedures of statistics a biometrical approach. In: KOGGAKUSHA (Ed.). Analysis of variance II: Multiway classifications, The randomized complite block design: more than one observation per treatment per block. 2.ed. Tokyo: McGRAW-HILL, 1980. Chap.9, p.195-238.

VENCOVSKY, R.; BARRIGA, P. Genética biométrica no fitomelhoramento: componentes da variação fenotípica. Análise em um ambiente. Ribeirão Preto: Revista Brasileira de Genética, 1992. Cap.3, p.83-232.

ZAFFARI, G.R. et al. Off-type micropropagated banana plants: endogenous levels of auxin, citokinins and IAA-oxidase. Acta Horticulturae, Brugge, v.520, p.219-227, 2000. 